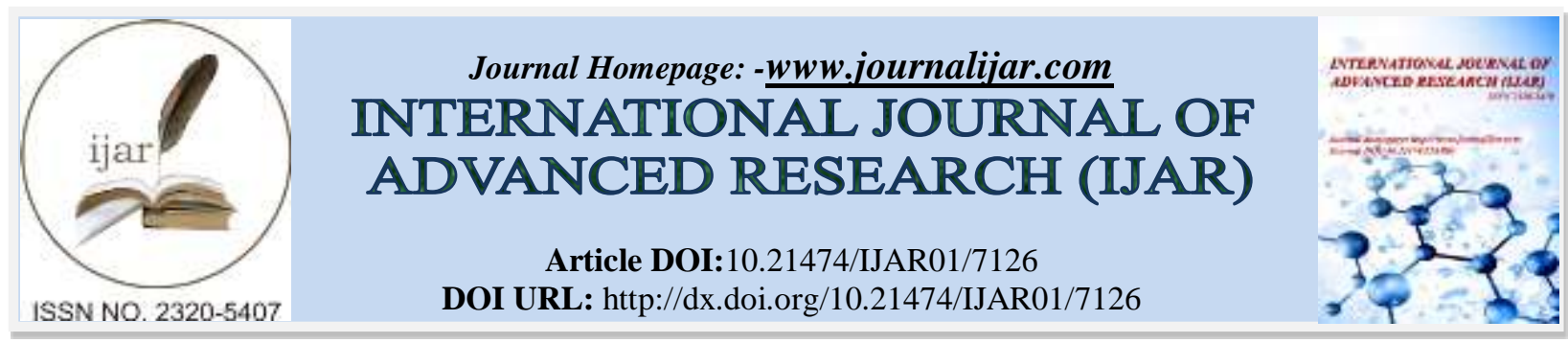

RESEARCH ARTICLE

\title{
EDIBLE OIL COMPOSITION FOR USE IN MULTIPURPOSE COOKING AND FRYING APPLICATIONS.
}

\section{Hanafy A. Hashem ${ }^{1}$, Rabie S. Farag ${ }^{2}$, Abdel-Alrahman Naser ${ }^{3}$, Montaser. A. Mohamed ${ }^{4}$ and Salma Foad $^{2}$ Gomaa ${ }^{4}$.}

1. Department of Food science \& technology-Faculty of Agriculture-Al-Azhar university.

2. Department of Inorganic \& Analytical Chemistry -Faculty of Science- -Al-Azhar university.

3. Department of Organic chemistry ( Oils\& fats ) -Faculty of Science -Al-Azhar university.

4. Innovation - R\&D center- Savola Foods Company, Cairo, Egypt.

\section{Manuscript Info}

\section{Manuscript History}

Received: 18 March 2018

Final Accepted: 20 April 2018

Published: May 2018

Keywords:-

Oil blending -Healthier impact Oxidative stability -sensory attributes-

Cooking and frying applications .

\begin{abstract}
Preparation of healthier cooking oils compositions that meet the standard limits of fatty acid composition for healthier oil established by international health authorities while meeting the oxidative stability criteria for cooking and frying applications is a unique target for most of cooking oil research studies done in the last few decades by different authors .

There are several research and investigations about the relationship between total fat intake and some common diseases that believed they were direct result of fat intake. Regarding total fat, for example, several recent reports of prospective observational studies found either no or small associations between total dietary fat intake and obesity, weight gain, coronary heart disease (CHD), and cancer risk. But the key point is how much and which composition we get from fat and oil sources.

A number of studies have been conducted on different oil blends. The target of those studies were either to reach a formula of higher oxidative stability during cooking and frying, or to reach a formula with healthier impact. Some of those blends have already reached the market as edible products. However, few studies are done to correlate between the better cooking and frying stability and healthier impact at the same time. In this review, number of formulas that have been prepared that can be used for either healthy purposes, or better oxidative stability. This review can help the oil producing industry to find out the most economically viable oil blends for cooking purposes, with maximum nutrition as well as desirable physico-chemical properties.

Copy Right, IJAR, 2018,. All rights reserved.
\end{abstract}

\section{Introduction:-}

Cooking Oil Is an edible oil that is liquid and clear at room temperature, $75 \mathrm{~F}$ or $23.9 \mathrm{C}$, that may be used for cooking. Cooking oils are typically used for vegetables cooking, Pan or shallow frying, deep-fat frying, sauces, gravies, marinates, and other non-refrigerated food preparations where a clear liquid oil has application. Cooking oils usually congeal or solidify at refrigerator temperatures. Ideal cooking and frying oils need to be more stable 
to oxidation than salad oil because of the higher temperatures to which cooking oils are exposed. Temperature stability is especially required in fats and oils used in shallow or deep-fat frying.

The oil is therefore the most critical and variable component in the frying operation, not only because of its wellknown instability under thermal stress, with the formation of degradation products, but also because of the physicochemical impact which conditions the frying operations and the characteristics of the fried product. At the high temperatures used during frying, the oil can undergo hydrolytic splitting, with the formation of partial glycerides and free fatty acids and a decrease of the smoke point; oxidation, with the formation of hydroperoxides which subsequently evolve with related cycling and rheological changes (with a negative effect on the viscosity of the oil) ; formation of splitting compounds such as polar compounds, compounds with a carbonyl and furan structure (responsible for the off-flavour) ; and formation of position isomers (conjugate acids) and structure isomers (trans acids) with suspected anti-nutritional activity. The frying cycle therefore causes an increase in the polarity of the water/oil system due to the reactivity of the oil used, with a negative effect on the physico-chemical and rheological characteristics of the product, combined with potential undesirable biological effects in the metabolic phase, such as the decrease of the nutritional value of the product and possible interference with endogenous enzyme activity during digestion and transport.

The above discussion demonstrates the need to provide oil compounds for frying and cooking which have a high stability under thermal stress, with less development of degradation products during frying and/or cooking and less absorption of these degradation products on the surface of the food.

On other side salad oils must be physically stable so that they do not crystalize at refrigerated temperatures.In this paper, a set of oil blends have been studied and conducted trials which enabled to identify some optimum blends for the preparation of vegetable oil mixtures in order to obtain edible oil compositions, particularly for frying and cooking food, which meet the aforementioned requirements.

There are some basic criteria has been identified by inventors for the preparation of vegetable oil mixtures in order to obtain edible oil compositions, particularly suitable for frying and cooking food, which meet the aforementioned requirements[1].

The substantial absence of medium- and short-chain fatty acids $(\mathrm{C}<12)$, in order to avoid rapid hydrolytic splitting of the triglycerides with formation of free fatty acids and polar compounds and consequent lowering of the smoke point; in this context, the expression "substantial absence" used above signifies a content of medium- and shortchain fatty acids $(\mathrm{C}<12)$ of less than $0.5 \%$ by weight of the total fatty acid content;

A balance in the mixture of oils, on the one hand between the monounsaturated fatty acids(MUFA) and the polyunsaturated fatty acids(PUFA), and on the other hand in the relative content of saturated fatty acids(SFA), in order to promote the oxidation stability of the oil while also controlling its rheological characteristics (particularly the dynamic viscosity and the specific density) ;

The presence in the oil mixture of an adequate quantity of antioxidant substances of natural origin, stable at the process temperature, which have potential synergic interactions without effects on the organoleptic qualities of the finished product.

The balance between MUFA and PUFA as well as the relative content of SFA are the key parameters of the oil system, since they can be used to modify the physico-chemical characteristics of the oil mixtures, for example their dynamic viscosity ( measured as the capillary flow in seconds at a constant temperature $20 \mathrm{C}$ ) and with a wide constant path, and have a direct relationship with the rate of absorption of the oil in the fried product.

The inventor therefore relates between the edible oil composition, particularly for use in frying and cooking foods, the said composition consisting of a mixture of vegetable oils characterized by a ratio by weight of (MUFA) to (PUFA) in the range from 5 to 8 , and preferably from 6 to 7 and a percentage of saturated fatty acids (SFA) in the range from $18 \%$ to $22 \%$, preferably $19 \%$ to $21 \%$, and a content of antioxidant substances in the range from 50 to 500 ppm, preferably 200 to $300 \mathrm{ppm}$. 
Oil Compositions having the characteristics specified above can be produced by mixing different vegetable oils, taking into account the known content of saturated and unsaturated (mono- and polyunsaturated) fatty acids of each oil in the mixture.

In this study a various oil blend composition of the mixture, has been studied while remaining within the ranges stated above in relation to the values of (MUFA :PUFA ) and considerable amount of (SFA) .

It was an advantageous aspect of the study, since it permits a degree of flexibility of production in respect of cost, availability and planning.

Another main advantage of blending that there is no any change of oil nature by any conversion process as hydrogenation or inter-esterification, so the obtained oil blends that fit the purpose of the study are claimed as hundred percent nature. The antioxidant used is not limited to synthetic types but also the natural antioxidants was selected to fulfil the claim of clean label and $100 \%$ natural product .

Also , it does not need any capital investments for manufacturers to produce the optimum healthy cooking oils as there is no capital investments in conversion units to change the nature of oil by fractionation or inter-estrificaton. The possibility of varying the vegetable oil composition of the mixture, while remaining within the ranges stated above in relations to the values of PUFA and SFA, is the scope and advantageous aspect of this study, since it permits a degree of flexibility of production in respect of cost, availability, simplicity and cost effectiveness .

Blending is defined as mixing of two or more ingredients to achieve the pre-set objectives. In blending, composite ingredients share advantages and disadvantages according to the blend ratio. When it comes to edible oils, blending can modify the physicochemical properties of oils without changing their chemical composition. Therefore, oils can be blended to derive the protective advantage due to the presence of specific ingredients that offer protection against oxidation to improve frying recyclability. Furthermore, Blending oils make it possible to get an ideal mix with the best of each raw material in terms of heath impact. Vegetable oils blend results in excellent color, natural taste and neutral flavor. It is ideal for frying and other industrial applications[3][4]

Oil Blends Of Healthier Impact (Smart Balance Formulas):-

WHO and FAO (2) standardized a limitations regarding the healthier total fat intake and the fatty acid composition for the healthier fat formulas..

1. The limitations regarding fat composition start with total fat intake. For adults 20-35\% of total energy should be provided by fat and oil. It consider the mean percentage $(30 \% \mathrm{E})$ as the basis for calculation the fatty acid limitations.

2. SFA: the optimum range is less that $10 \% \mathrm{E}$ or less than $33 \%$ of total fat.

3. Considering the healthier impact of individual saturated fatty acids composition, the lauric (C12:0), myristic (C14:0) and palmitic (C16:0) acids increase LDL cholesterol whereas stearic (C18:0) has no effect.

4. Replacing SFA (C14:0 and C16:0) by PUFA reduce LDL and Total HDL concentration but replacing by MUFA have lesser effect. Replacing SFA with PUFA decreases the risk of CHD.

5. -There is a possible positive relationship between SFA intake and increased risk of diabetes.

6. n-6 PUFA: the optimum range is $8.3-9 \% \mathrm{E}$ (energy percentage) or $8.3-30 \%$ of total fat.

7. n-3 PUFA: the optimum range is $0.5-2 \% \mathrm{E}$ or $1.7-6.6 \%$ of total fat.

8. PUFA: the optimum range is $6-11 \% \mathrm{E}$ or $20-36 \%$ of total fat.

9. SFA: the optimum range is less that $10 \% \mathrm{E}$ or less than $33 \%$ of total fat.

10. MUFA: there is no limitation for MUFA and determined by difference i.e.

MUFA $=$ Total fat intake $(\% \mathrm{E})-$ SFA (E\%) - PUFA (E\%) - TFA (\%E).-

Replacing Carbohydrates with MUFA increases HDL cholesterol concentrations.

The lower value or AI (2.5-3.5\% E) corresponds to the prevention of deficiency symptoms, whereas the higher value as part of a healthy diet contributing to long term health by lowering LDL and total cholesterol levels and therefore the risk for CHD.

A number of studies have been conducted before on different oil blends. The target of those studies were either to reach a formula of higher oxidative stability during cooking and frying, or to reach a formula with healthier impact. Some of those blends have already reached the market as edible products. However, few studies are done to correlate between the better cooking and frying stability and healthier impact at the same time [3]. In this review, number of formulas that have been addressed and studied that can be used for either healthy purposes, or better 
oxidative stability. This review can help the oil producing industry to find out the most economically viable oil blends for cooking purposes, with maximum nutrition as well as desirable physico-chemical properties.

According to the nutritional guidelines, such as AHA / WHO guideline, vegetable oil blends that can satisfy a ratio of 1:1:1 between SAFA, MUFA \& PUFA is considered the optimum smart blends regarding to health impact. Blend of palm olein \&SBO (50:50) and that of palm olein: sesame oil (52:48) can satisfy the requirement of the optimum smart blend of SAFA: MUFA: PUFA ratio 1:1:1[5].

In this study, the different sources of vegetable oils including but not limited to Soybean, Sunflower, Canola, Olive, Corn and palm fractions, etc. are utilized to make proposed combinations as listed in table 1 . The selected formulas were derived by minimizing the SFA and replace it by PUFA. This is because of the studies done which indicates that replacing SFA (C14:0 and C16:0) by PUFA reduce LDL and Total/HDL concentration. Also replacing SFA with PUFA decreases the risk of CHD (Coronary Heart Disease). However, replacing by MUFA have lesser effect [4].

Table 1:-proposed smart formulas without olive oil

\begin{tabular}{|c|c|c|c|c|c|c|c|}
\hline No & OIL BLEND & CONTENT & $\begin{array}{l}\text { SFA } \\
\leq 33 \%\end{array}$ & MUFA & $\begin{array}{l}\text { PUFA } \\
20-36 \%\end{array}$ & $\begin{array}{l}\text { n-3 PUFA } \\
1.7-6.6 \%\end{array}$ & $\begin{array}{l}\text { n-6 PUFA } \\
8.3-30 \%\end{array}$ \\
\hline & \multicolumn{2}{|l|}{ MEAN RANGE } & $16.5 \%$ & & $28 \%$ & $4.15 \%$ & $19.15 \%$ \\
\hline \multirow[t]{2}{*}{$1-$} & DF & $20 \%$ & \multirow[t]{2}{*}{13.20} & \multirow[t]{2}{*}{54.7} & \multirow[t]{2}{*}{25.70} & \multirow[t]{2}{*}{6.00} & \multirow[t]{2}{*}{19.70} \\
\hline & CANOLA & $80 \%$ & & & & & \\
\hline \multirow[t]{2}{*}{$2-$} & CORN & $20 \%$ & \multirow[t]{2}{*}{8.20} & \multirow[t]{2}{*}{51.60} & \multirow[t]{2}{*}{32.00} & \multirow[t]{2}{*}{6.20} & \multirow[t]{2}{*}{25.80} \\
\hline & CANOLA & $80 \%$ & & & & & \\
\hline \multirow[t]{2}{*}{$3-$} & CANOLA & $80 \%$ & \multirow[t]{2}{*}{7.70} & \multirow[t]{2}{*}{51.60} & \multirow[t]{2}{*}{34.10} & \multirow[t]{2}{*}{6.10} & \multirow[t]{2}{*}{28.00} \\
\hline & SUNFLOWER & $20 \%$ & & & & & \\
\hline \multirow[t]{3}{*}{ 4- } & DF & $10 \%$ & \multirow[t]{3}{*}{10.45} & \multirow[t]{3}{*}{53.15} & \multirow[t]{3}{*}{29.90} & \multirow[t]{3}{*}{6.05} & \multirow[t]{3}{*}{23.85} \\
\hline & CANOLA & $80 \%$ & & & & & \\
\hline & SUNFLOWER & $10 \%$ & & & & & \\
\hline \multirow[t]{3}{*}{$5-$} & CORN & $10 \%$ & \multirow[t]{3}{*}{10.70} & \multirow[t]{3}{*}{53.15} & \multirow[t]{3}{*}{28.85} & \multirow[t]{3}{*}{6.10} & \multirow[t]{3}{*}{22.85} \\
\hline & DF & $10 \%$ & & & & & \\
\hline & CANOLA & $80 \%$ & & & & & \\
\hline
\end{tabular}

Table 2:-Proposed Smart Formulas With Olive Oil

\begin{tabular}{|c|c|c|c|c|c|c|c|}
\hline No & OIL BLEND & RATIO & $\begin{array}{l}\text { SFA } \\
\leq 33 \%\end{array}$ & MUFA & $\begin{array}{l}\text { PUFA } \\
20-36 \%\end{array}$ & $\begin{array}{l}\text { N-3 PUFA } \\
1.7-6.6 \%\end{array}$ & $\begin{array}{l}\text { N-6 PUFA } \\
8.3-30 \%\end{array}$ \\
\hline \multicolumn{3}{|c|}{ MEAN RANGE } & $16.5 \%$ & & $28 \%$ & $4.15 \%$ & $19.15 \%$ \\
\hline \multirow[t]{2}{*}{1} & OLIVE & $50 \%$ & \multirow[t]{2}{*}{11.00} & \multirow[t]{2}{*}{66.00} & \multirow[t]{2}{*}{32.65} & \multirow[t]{2}{*}{4.15} & \multirow[t]{2}{*}{14.50} \\
\hline & CANOLA & $50 \%$ & & & & & \\
\hline \multirow[t]{2}{*}{2} & SOYA & $40 \%$ & \multirow[t]{2}{*}{15.00} & \multirow[t]{2}{*}{54.20} & \multirow[t]{2}{*}{28.68} & \multirow[t]{2}{*}{2.68} & \multirow[t]{2}{*}{26.00} \\
\hline & OLIVE & $60 \%$ & & & & & \\
\hline \multirow[t]{3}{*}{3} & CANOLA & $10 \%$ & \multirow[t]{3}{*}{8,15} & \multirow[t]{3}{*}{56.10} & \multirow[t]{3}{*}{29.33} & \multirow[t]{3}{*}{6.13} & \multirow[t]{3}{*}{23.20} \\
\hline & SUNFLOWER & $80 \%$ & & & & & \\
\hline & SOYA & $10 \%$ & & & & & \\
\hline \multirow[t]{3}{*}{4} & SUNFLOWER & $10 \%$ & \multirow[t]{3}{*}{14.55} & \multirow[t]{3}{*}{54.90} & \multirow[t]{3}{*}{29.20} & \multirow[t]{3}{*}{2.18} & \multirow[t]{3}{*}{26.30} \\
\hline & SOYA & $30 \%$ & & & & & \\
\hline & OLIVE & $60 \%$ & & & & & \\
\hline \multirow[t]{3}{*}{5} & CORN & $10 \%$ & \multirow[t]{3}{*}{8.40} & \multirow[t]{3}{*}{56.10} & \multirow[t]{3}{*}{28.28} & \multirow[t]{3}{*}{6.18} & \multirow[t]{3}{*}{22.10} \\
\hline & OLIVE & $10 \%$ & & & & & \\
\hline & CANOLA & $80 \%$ & & & & & \\
\hline \multirow[t]{3}{*}{6} & CANOLA & $40 \%$ & \multirow[t]{3}{*}{11.80} & \multirow[t]{3}{*}{62.60} & \multirow[t]{3}{*}{32.85} & \multirow[t]{3}{*}{3.95} & 17.70 \\
\hline & SOYA & $10 \%$ & & & & & \\
\hline & OLIVE & $50 \%$ & & & & & \\
\hline
\end{tabular}




\section{Oil blends with higher stability during frying:-}

Oils and fats intended for commercial frying applications must be stabilized to prevent deterioration caused by oxidation, polymerization, and hydrolysis during high-temperature use. Modifying the fatty acid composition of the oil - the most common method to stabilize frying oils - can be done by several methods. For example, blending polyunsaturated oils with more saturated or monounsaturated oils is an option to adjust fatty acid levels to optimal levels, such as combining high-oleic sunflower oil with corn oil or hydrogenated soybean oil with soybean oil (1517). Chemically altering the existing fatty acid ratios by hydrogenation increases saturated fatty acids and decreases polyunsaturated fatty acids to produce a more stable oil (17-18).

The suitability of a oils for cooking purpose depends on the extent to resist oxidation under harsh conditions of frying regarding exposure to heating and aerobic conditions.

The oxidized fats in a very high dosage have been shown to have toxic effects. Therefore, studies in which degradation of frying oils is measured and analysis of rancidity volatiles are valuable in understanding the oil oxidation state. Although quality of pure vegetable oils before and after frying has been evaluated by many researchers but the physicochemical properties for binary oil blends have not been studied extensively. Some of this studies are summarized in the following section based on the type of vegetable oil used[6][7] [8].

\section{Vegetable oil blends based on sesame:-}

Sesame oil contains $45-49 \%$ monounsaturated fatty acids and $37 \%$ to $41 \%$ polyunsaturated fatty acids which are more prone to auto-oxidation and hydrolytic reaction during frying. However, the presence of the thermally stable lignans in the oil offers protection against oxidation[5].

\section{Sesame-rice bran and sesame-cotton seed blends:-}

A number of studies has been done on the effect of adding sesame oil on different vegetable oils. The effect of adding sesame oil on cotton seed and rice bran, in terms of stability during frying, has been studied. In this study, two main ratios of Sesame oil: other vegetable oil were used (20:80 and 80:20). The oil blends were used for frying ready to eat (RTE) snacks. The oil was extracted from the products via soxhlet apparatus. The extracted oil was then analyzed for various rancidity parameters, such as peroxide value, free fatty acid and anisidine value. It was observed that the addition of sesame oil improved the stability of cotton seed oil and rice bran oil, in terms of their peroxide value. It was also observed that sesame: rice bran and sesame: cotton seed showed the best oxidative stability in terms of all the analysis tests.

Table 3:-Oxidative stability of Sesame-rice bran -sesame-cotton seed oil and sesame: palm olein oil blends after frying.

\begin{tabular}{|l|l|l|l|l|}
\hline No & & PV $(\mathrm{meq} / \mathrm{Kg})$ & P-AV & FFA\% \\
\hline 1 & $\begin{array}{l}\text { Sesame: rice bran } \\
(80: 20)\end{array}$ & $3.328 \pm 0.058$ & $8.306 \pm 0.602$ & $1.09 \pm 0.010$ \\
\cline { 2 - 5 } & $\begin{array}{l}\text { Sesame: rice bran } \\
(20: 80)\end{array}$ & $4.580 \pm 0.401$ & $17.99 \pm 0.702$ & $0.19 \pm 0.110$ \\
\hline 2 & $\begin{array}{c}\text { Sesame: cotton seed } \\
(80: 20))\end{array}$ & $4.098 \pm 0.588$ & $6.196 \pm 0.775$ & $1.45 \pm 0.269$ \\
\cline { 2 - 5 } & $\begin{array}{c}\text { Sesame: cotton seed } \\
(20: 80)\end{array}$ & $4.057 \pm 0.231$ & $6.636 \pm 0.376$ & $0.13 \pm 0.144$ \\
\hline
\end{tabular}

According to the WHO and FAO standards for healthier formulas, the formula of sesame: rice bran (20:80) can be classified as smart formula (see table 4) Also, it shows better stability during frying, thus it can be considered as a promising stable frying and cooking medium.

Table 4:-Smart balance formula for sesame: rice bran blends

\begin{tabular}{|c|c|c|c|c|c|c|c|}
\hline $\mathrm{No}$ & OIL BLEND & RATIO & $\begin{array}{l}\text { SFA } \\
\leq 33 \%\end{array}$ & MUFA & $\begin{array}{l}\text { PUFA } \\
20-36 \%\end{array}$ & $\begin{array}{l}\text { N-3 PUFA } \\
1.7-6.6 \%\end{array}$ & $\begin{array}{l}\text { N-6 PUFA } \\
8.3-30 \%\end{array}$ \\
\hline \multicolumn{3}{|c|}{ MEAN RANGE } & $16.5 \%$ & & $28 \%$ & $4.15 \%$ & $19.15 \%$ \\
\hline 1 & Sesame:Rice bran & $80: 20$ & 19.2 & 33.6 & 27.2 & 1.2 & 26 \\
\hline
\end{tabular}




\section{Vegetable oil blends based on Palm oil and palm olein:-}

Recently, palm oil has become the second most consumed oil all over the world with a competitive price compared to other edible oils. Palm oil and its fractions, including palm olein, is accepted as a frying oil because of its tocols and carotenoids composition, and its relative proportion of unsaturated and saturated fatty acid content. However, due to its high melting point, it is not gaining due status in spite of being rich in natural antioxidants, vitamins, high oxidative stability and having a long self-life. Palm oil is also rich in $\beta$-carotene which helps to prevent liver and lung cancer. Number of studies have been conducted on blending palm oil with different vegetable soft oils in order to improve its cold stability at lower temperatures[5][7].

Palm Olein-Canola oil and Palm olein-soybean blend:-

Another study has been conducted on blends of palm olein (PO) with canola oil (CO), sunflower oil (SF), and soybean oil (SO). The main aim of this work was to study the change in physical and chemical properties of such vegetable oils such as palm olein (PO), canola oil (CO), sunflower oil (SF), soybean oil (SO) when they are blended with one another in different mixing ratios. It is also aimed at finding a blend of oxidatively stable palm olein with low melting points by adding vegetable oils with high degrees of unsaturation. In this study, Oil blends were prepared by mixing palm olein with blending oil $(\mathrm{w} / \mathrm{w})$ in different ratios ranging from 10:90 to 90:10. The mixtures were stirred in a magnetic stirrer for 20 minutes for homogenization. The PV of the oils and their blends was determined in 8 week intervals while all the oil samples were kept in uncovered beakers at room temperature during this time. Canola-palm blend was found to be as low as 40 meq O2/kg oil. The initial PV value and after 3 weeks for palm olein-canola blends was found to be almost the same, although after 8 weeks it was lower than the others. The natural antioxidants in both palm and canola oil hinder the oxidation process considerably in this oil blend compared to the others. Also the results revealed that palm olein-canola blend has more resistance against oxidation and melting point, which was also found to be lower for this blend, followed by palm olein-soybean and palm oleinsunflower blends[9]. According to the FOA/WHO standards, the smart balance formulas for Palm olein: canola blends are within the ratios 60:40, 50:50, 40:60 and 30:70 (see table 5).

Table 5:-Smart balance formula for palm olein: canola blends

\begin{tabular}{|c|c|c|c|c|c|c|c|}
\hline No & OIL BLEND & RATIO & $\begin{array}{l}\text { SFA } \\
\leq 33 \%\end{array}$ & MUFA & $\begin{array}{l}\text { PUFA } \\
20-36 \%\end{array}$ & $\begin{array}{l}\text { N-3 PUFA } \\
1.7-6.6 \%\end{array}$ & $\begin{array}{l}\text { N-6 PUFA } \\
8.3-30 \%\end{array}$ \\
\hline \multicolumn{3}{|c|}{ MEAN RANGE } & $16.5 \%$ & & $28 \%$ & $4.15 \%$ & $19.15 \%$ \\
\hline 1 & \multirow{4}{*}{ Palm olein: Canola } & $60: 40$ & 30.6 & 50 & 19.4 & 4 & 15.3 \\
\hline 2 & & $50: 50$ & 26.5 & 52 & 21.5 & 5 & 16.5 \\
\hline 3 & & $40: 60$ & 22.4 & 54 & 23.6 & 6 & 17.6 \\
\hline 4 & & $30: 70$ & 18.3 & 56 & 25.7 & 7 & 18.6 \\
\hline
\end{tabular}

Palm oil-Sesame blends:-

Another study was done on the effect of blending Palm oil with sesame oil in different ratios to get blends with low cost and better nutritional advantage relative to sesame. The ratios of blends used were (20:80) and (80:20) PO to $\mathrm{SeO}$. A blend of $\mathrm{PO}$ with $\mathrm{SeO}$ is also prepared with saturated acid : Monounsaturated acid: Polyunsaturated acid (S: M: P) in ratio 1:1:1 in view of its nutritional significance. This can be achieved by blending with a ratio (52:48), PO to $\mathrm{SeO}$. Studies were conducted on individual and blended oils to determine thermal stability at $180^{\circ} \mathrm{C}$ in oven for 12 hours and during deep fat frying (DFF) of dry potato chips at $180 \mathrm{C}$ for 9 hours. The individual and blended oils were analyzed for physio-chemical properties during thermal stability study including Iodine value (IV) acid value (AV), peroxide value (PV) and color. It was concluded from the study that the blends of $\mathrm{PO}$ with $\mathrm{SeO}$ in different proporations are more stable to oxidatuve deterioration due to heating as compared to $\mathrm{SeO}$ (see table 6). Addition of $\mathrm{PO}$ to the $\mathrm{SeO}$ means longer frying times for the latter and could make the PO acceptable to the consumers who prefer foods with aroma and flavor impared by $\mathrm{SeO}$. The protection affored by $\mathrm{PO}$ to $\mathrm{SeO}$ increased with increasing in proportion of $\mathrm{PO}$ in blends[4].

Table 6:-Physio-chemical characterization of Palm: sesame oils blends during thermal stability study.

\begin{tabular}{|c|c|c|c|c|}
\hline Oil/Blends & \multicolumn{4}{|c|}{ Part-A initial values } \\
\hline & AV & IV & PV & Color (Red) \\
\hline Palm pure & 2.54 & 52.50 & 2.80 & 5.30 \\
\hline PO:SeO (80:20) & 2.74 & 70.97 & 3.50 & 5.80 \\
\hline PO: $\mathrm{SeO}(20: 80)$ & 3.05 & 86.96 & 5.70 & 6.70 \\
\hline
\end{tabular}




\begin{tabular}{|c|c|c|c|c|}
\hline PO:SeO (52:48) & 3.50 & 96.29 & 6.80 & 7.20 \\
\hline Sesame pure & 3,72 & 111.79 & 3.363 & 7.90 \\
\hline & \multicolumn{4}{|c|}{ Part-B Fianl value } \\
\hline & AV & IV & PV & Color \\
\hline Palm Pure & 3.24 & 51.10 & 3 & 5.89 \\
\hline PO:SeO (80:20) & 3.45 & 69.09 & 3.75 & 6.60 \\
\hline PO: SeO $(20: 80)$ & 3.78 & 84.66 & 6.11 & 7.80 \\
\hline PO:SeO (52:48) & 4.30 & 93.79 & 7.30 & 8.60 \\
\hline \multirow[t]{2}{*}{ Sesame pure } & 4.50 & 108.89 & 3.90 & 9.70 \\
\hline & \multicolumn{4}{|c|}{ Part C-Difference } \\
\hline Palm Pure & $\triangle \mathrm{AV}(\%)$ & $\Delta \operatorname{IV}(\%)$ & $\Delta \mathrm{PV}(\%)$ & $\Delta$ Color $(\%)$ \\
\hline PO:SeO (80:20) & 27.55 & 2.66 & 7.14 & 11.13 \\
\hline PO: $\mathrm{SeO}(20: 80)$ & 25.91 & 2.67 & 7.14 & 13.79 \\
\hline PO:SeO (52:48) & 23.93 & 2.64 & 7.19 & 16.41 \\
\hline Sesame pure & 22.85 & 2.59 & 7.35 & 19.44 \\
\hline
\end{tabular}

Apart from protection advantage, blend with $\mathrm{PO}: \mathrm{SeO}$ ratio 52:48, with its ideal fatty acid composition of 1:1:1 of SUFA:MUFA:PUFA, can offer a nutritional advantage frying medium (see table 7).

Table 7:-Smart balance formula for palm oil: sesame blends

\begin{tabular}{|l|l|c|l|l|l|l|l|}
\hline NO & OIL BLEND & RATIO & $\begin{array}{l}\text { SFA } \\
\leq 33 \%\end{array}$ & MUFA & $\begin{array}{l}\text { PUFA } \\
20-36 \%\end{array}$ & $\begin{array}{l}\text { N-3 PUFA } \\
1.7-6.6 \%\end{array}$ & $\begin{array}{l}\text { N-6 PUFA } \\
8.3-30 \%\end{array}$ \\
\hline \multicolumn{3}{|c|}{ MEAN RANGE } & $16.5 \%$ & & $28 \%$ & $4.15 \%$ & $19.15 \%$ \\
\hline $1-$ & Palm Oil: Sesame Oil & $52: 48$ & 32.58 & 40.52 & 27.16 & $\underline{\mathbf{0 . 1 5}}$ & 26 \\
\hline
\end{tabular}

Vegetable oil blends based on coconut:-

Coconut oil has been classified as functional food owing to its health beneficial properties. Coconut oil is composed predominately of medium-chain fatty acids (MCFA), also known as medium-chain triglycerides (MCT) (14-15\%). MCFA are very different from LCFA. They do not have a negative effect on cholesterol and help to protect against heart disease. MCFA help to lower the risk of both atherosclerosis and heart disease. It is primarily due to the MCFA in coconut oil that makes it so special and so beneficial [10]. Due to the presence of MCFA, which are more soluble in water than LCFA. Coconut oil is more prone to hydrolytic oxidation. Susceptibility of coconut oil to hydrolytic oxidation can be minimized by blending with other oils of more stability[10][11].

\section{Coconut-palm olein and coconut-sesame blends:-}

A study was done on the effect of blending coconut oil with palm olein and sesame oil. The objective of this study was to assess the acceptance of using coconut as a deep frying medium by blending it with sesame oil and palm olein, separately with the ratio $1: 1$, and to determine the stability and sensory quality of the blended oils during frying. The oil blends was prepared by a ratio $(1: 1)$.

Blends of coconut oil with sesame oil (blend 1); coconut olein with sesame oil (blend 2); coconut olein with palmolein (blend 3) in 1:1 (v/v) ratio-were used in this study for frying Poori, a traditional Indian fast food prepared from wheat flour. Changes in oil quality were determined by chemical and sensory methods. Free fatty acid content did not change whereas peroxide value increased. Anisidine value increased from 5.5, 0.9 and 4.2 to 34.3, 42.8 and 23.6 for blends 1,2 and 3, respectively. Iodine value showed marginal decrease in blends 1 and 2 . Diene value showed no change in all three blends (See table 6). Sesamol content in blends 1 and 2, total tocopherols in all the three blends, and $\beta$-carotene.

Content in blend 3 decreased after frying. The blends showed a significant decrease $(\mathrm{P} \leq 0.05)$ in the characteristic coconut oil odor after frying. Blend 3 showed comparatively better frying stability and also overall sensory quality of poori fried in this blend was the highest[11].

Table 6:-Change in chemical parameters of coconut oil blends during frying

\begin{tabular}{|l|l|l|l|l|l|l|}
\hline Sample & No of fryings & FFA\% & PV (meqO2/Kg) & IV (Wijs) & AV & Diene (\%) \\
\hline Blend 1 & 0 & 0.9 & 0 & 59.2 & 5.5 & 0.2 \\
\hline
\end{tabular}




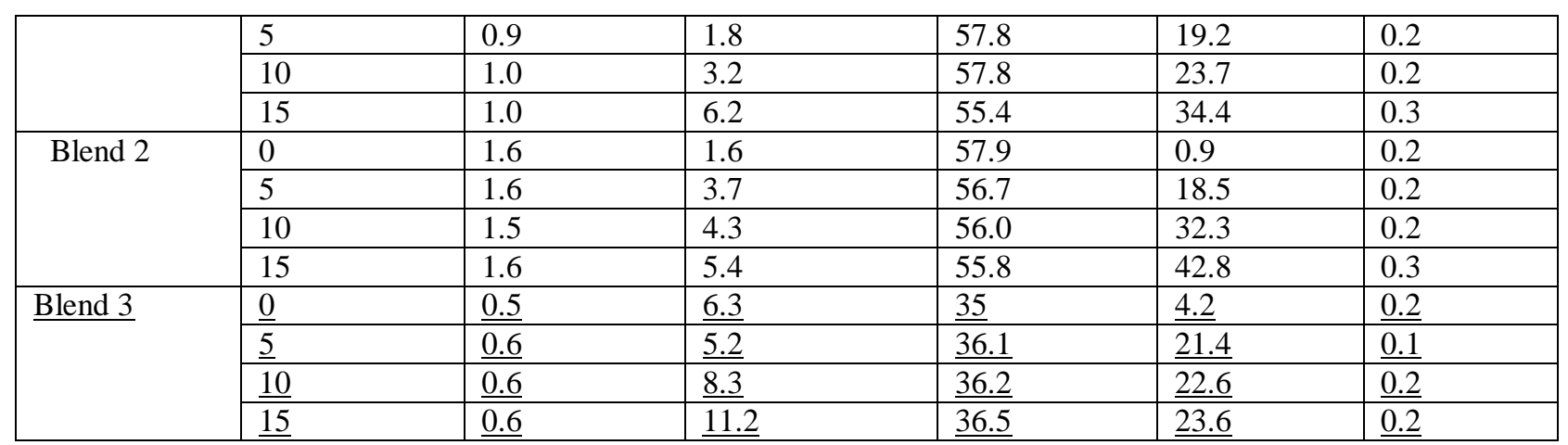

Vegetable oil blends based on cold pressed oils:-

The consumption of health-promoting products such as cold pressed oils may improve human health and prevent certain diseases[12].

\section{Sunflower- and cold pressed oils:-}

Blends (10\% and 20\%, w/w) of cold pressed oils including black cumin oil (BC), cumin oil (Cum), coriander oil (Cor) and clove oil (Clo) with high linoleic sunflower oil (SF) were formulated. Oxidative stability (OS) and radical scavenging activity (RSA) of SF and blends stored under oxidative conditions $\left(60^{\circ} \mathrm{C}\right)$ for 8 days were studied. By increasing the proportion of cold pressed oils in SF, linoleic acid level decreased, while tocols level increased. Progression of oxidation was followed by measuring peroxide value (PV), p-anisidine value (Av), conjugated dienes (CD) and conjugated trienes (CT). Inverse relationships were noted between PV as well as Av and OS at termination of storage.

Levels of CD and CT in SF and blends increased with increase in time. Cold pressed oil blends gave about 70\% inhibition of DPPH • radicals. Oxidative stabilities of oil blends were better than SF, most likely as a consequence of changes in fatty acids and tocols' profile, and minor bioactive lipids found in cold pressed oils[12].

Blends consisting of sunflower oil and cold pressed tiger nut oil in different proportions were evaluated for various physicochemical parameters over 30 hours of frying process. The main objective of the study was to evaluate the effects of fatty acid compositions of tiger nut oil, sunflower oil and binary mixtures of them on the changes in physicochemical parameters of during deep frying process by assessing Free Fatty Acid (FFA), Peroxide Value (PV), thiobarbituric acid value (TBA value), iodine value, Total Polar Compounds (TPC), color and viscosity of the oils. Native and blended oils were heated at $180^{\circ} \mathrm{C}+5^{\circ} \mathrm{C}$, then frozen French fries potato were fried every $30 \mathrm{~min}$. Oil samples were taken every 5 hours and the entire continuous frying period was 30 hours. The results showed that phenolic content of cold pressed tiger nut oil was about 3.3 times higher than that of sunflower oil. The analytical data showed that the lowest deterioration during frying process occurred in tiger nut oil and the highest in sunflower. It also showed that tiger nut oil had higher level of total polyphenols which was $16.5 \mathrm{mg}$ GAE per $100 \mathrm{~g}$ of oil compared to sunflower oil $5.0 \mathrm{mg}$ GAE per $100 \mathrm{~g}$ of oil. At the same time, blending sunflower oil with various portions of tiger nut oil as a source of phenolic compounds and MUFA was suggested for improving the quality and the stability of sunflower oil during frying process. Our findings indicate that the changes of physicochemical parameters were controlled and significantly $(\mathrm{P}<0.05)$ decreased when tiger nut / sunflower oil $(\mathrm{W} / \mathrm{W})$ proportions were varied between $20 / 80$ to 50/50. These blended oils had better stability against oxidation during deep fat frying process[13].

Table 6:-Oxidative stability of sunflower blended with different portions of tiger nut oil after $30 \mathrm{hr}$ frying at $180^{\circ} \mathrm{C}$.

\begin{tabular}{|c|c|c|c|c|c|c|c|}
\hline \multirow[t]{2}{*}{ Oxidative test } & \multirow{2}{*}{$\begin{array}{l}\text { Tiger nut } \\
\text { oil (TNO) }\end{array}$} & \multirow{2}{*}{$\begin{array}{l}\text { Sunflower } \\
\text { Oil (SO) }\end{array}$} & \multicolumn{5}{|c|}{ TNO+SO } \\
\hline & & & $10: 90$ & $20: 80$ & $30: 70$ & $40: 60$ & $50: 50$ \\
\hline $\mathrm{PV}$ (meq.O2/Kg) & 6.51 & 9.64 & 8.98 & 8.41 & 7.63 & 7.44 & 6.76 \\
\hline TPC $(\% \mathrm{~W})$ & 13.61 & 19.40 & 18.00 & 16.92 & 15.95 & 14.46 & 14.32 \\
\hline $\begin{array}{l}\text { Viscosity ( } \mathrm{mPa}-\mathrm{S} \text { at } \\
30^{\circ} \mathrm{C} 0\end{array}$ & 59 & 70.50 & 65.00 & 64.00 & 62.50 & 61.00 & 60.10 \\
\hline Red color & 14.50 & 17 & 16.50 & 15.50 & 15.50 & 15 & 14.50 \\
\hline Thiobarbituric acid & 0.55 & 0.97 & 0.81 & 0.73 & 0.70 & 0.65 & 0.61 \\
\hline
\end{tabular}


value

In spite of the great importance of the concept of blending in edible oil industry, there are still a lot of aspects that are not been totally studied and discussed for industrial scale applications. For example, limited study has discussed the use of rice bran and its blends as a stable frying medium. In a study that was conducted to compare between the oxidative stability of palm olein (PO), the most stable fat frying medium, and rice bran (RBO) regarding their oxidative stability, RBO showed better stability than the PO in deep frying of French fries[14]. Also, in spite of the health assumptions of the cold pressed oils, and the few studies that have been conducted on their stability, the use of edible oils based on cold -pressed oil has not been widely introduced for the industrial applications.

Because of the attention that have been given to health consequences related to fat dietary intake, there is an increased demand for exploring new fat mediums that can be of good health impact and at the same time of suitable for different food practices form salad dressing to frying.

\section{Conclusion and future prospective:-}

In conclusion, The Optimum selection of oil blend that having the balanced fatty acid compositions, in addition to the right fatty acid types which are naturally more stable when subjected to drastic cooking and frying conditions in domestic applications, is very cost effective technique for oil producers to produce a healthier and functionally durable general purpose cooking \& frying oils aimed at improved and extended physical, chemical and functional properties. It is clear from the above studies that the oxidative stability, iodine value and peroxide value can be improved in this way to get good and desirable blends which will help to provide precise stability data. For example, the stability of unsaturated vegetable oils can be increased by blending with stable oil that has high saturation.

In spite of the great importance of the concept of the above optimum blending ratios between different types of vegetable oils edible oil industry to achieve the optimum healthier and functional oil blend, there will be still a lot of work to be done to explore a single oil type which is naturally carry these benefits with no blending with other oils and be available to oil producers .

\section{References:-}

1. WIPO Patent Application WO/2007/049227

2. 2010. Fats and fatty acids. Rome : Food and Agriculture Organization of the United Nations, 2010.

3. E. Choe and D. B. Min, "Chemistry of deep-fat frying oils," J. Food Sci., vol. 72, no. 5, 2007.

4. E. De Marco, M. Savarese, C. Parisini, I. Battimo, S. Falco, and R. Sacchi, "Frying performance of a sunflower/palm oil blend in comparison with pure palm oil," Eur. J. Lipid Sci. Technol., vol. 109, no. 3, pp. 237-246, 2007.

5. M. R. Tiwari, K. K. Tiwari, and S. D. Toliwal, "Studies on Thermal Stability of Palm -Sesame oil blends during Deep Fat Frying," vol. 73, no. March, pp. 153-156, 2014.

6. K. Warner and S. Knowlton, "Frying quality and oxidative stability of high-oleic corn oils," J. Am. Oil Chem. Soc., vol. 74, no. 10, pp. 1317-1322, 1997.

7. "Palm Olein Improves Cooking Oil Blends.pdf." .

8. E. M. Marinova, K. a. Seizova, I. R. Totseva, S. S. Panayotova, I. N. Marekov, and S. M. Momchilova, "Oxidative changes in some vegetable oils during heating at frying temperature," Bulg. Chem. Commun., vol. 44, no. 1, pp. 57-63, 2012.

9. B. Mobin Siddique, A. Ahmad, M. Hakimi Ibrahim, S. Hena, M. Rafatullah, and M. Omar A. K, "Physicochemical properties of blends of palm olein with other vegetable oils," Grasas y Aceites, vol. 61, no. 4, pp. 423429, 2010.

10. S. P. Koh and K. Long, "Oxidative stability study of virgin coconut oil during deep frying," J. Trop. Agric. Fd. Sc, vol. 40, no. 1, pp. 35-44, 2012.

11. M. I. Khan, M. R. Asha, K. K. Bhat, and S. Khatoon, "Studies on chemical and sensory parameters of coconut oil and its olein blends with sesame oil and palmolein during wheat flour-based product frying," J. Food Sci. Technol., vol. 48, no. 2, pp. 175-182, 2011.

12. M. F. Ramadan, "Healthy blends of high linoleic sunflower oil with selected cold pressed oils: Functionality, stability and antioxidative characteristics," Ind. Crops Prod., vol. 43, no. 1, pp. 65-72, 2013.

13. R. FM Ali, "Physicochemical Studies on Sunflower Oil Blended with Cold Pressed Tiger Nut Oil, during Deep Frying Process,” J. Food Process. Technol., vol. 03, no. 08, 2012.

14. H. Y. Fan, M. S. Sharifudin, M. Hasmadi, and H. M. Chew, "Frying stability of rice bran oil and palm olein," Int. Food Res. J., vol. 20, no. 1, pp. 403-407, 2013. 
15. Frankel, E.N., and S.W. Huang, Improving the Oxidative Stability of Polyunsaturated Vegetables Oils by Blending with High-Oleic Sunflower Oil, J. Am Oil Chem. Soc. 71:255-259 (1994).

16. Moulton, K.J., R.E. Beal, K. Warner, and B.K. Boundy, Flavor Evaluation of Copper-Nickel Hydrogenated Soybean Oil and Blends with Unhydrogenated Oil, Ibid. 52:469-472 (1975).

17. Cowan, J.C., S. Koritala, K. Warner, G.R. List, K.J. Moulton, and C.D. Evans, Copper-Hydrogenated Soybean and Linseed Oils: Composition, Quality and Oxidative Stability, Ibid. 50:132-136 (1973).

18. Frankel, E.N., K. Warner, and K.J. Moulton, Effects of Hydrogenation and Additives on Cooking Oil Performance of Soybean Oil, Ibid. 62:1354-1358 (1985). 